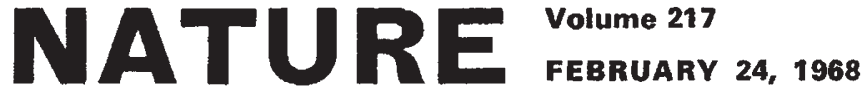

\section{What Price Roads?}

Romantic attitudes towards highways must now be almost extinguished in industrial societies, what with traffic accidents, air pollution and the like. Any doubts that may remain will, however, be dispelled by the appearance in the past week of a series of economic calculations by the Ministry of Transport which is intended as a basis for future attempts to apportion the costs of operating the highways system between the different classes of road users (Road-Track Costs, HMSO, 11s.). In practice, the study is an attempt to apply in British conditions some of the methods which have been developed elsewhere in the past decade or so, particularly in the United States and Canada. The British document is more than a mere academic study, however, for it is plainly intended as a theoretical justification of the decision by the Ministry of Transport to levy higher charges on heavy goods vehicles using British roads-one of the several controversial aspects of the traffic legislation with which the British Parliament is at present exercised. Indeed, there is some internal evidence that the economic argument, which is intricate enough to satisfy any taste, would have been more valuable if its authors had had more time to think about it.

The essence of the difficulty is that a road system is an integrated whole which is used as a whole by all kinds of users. The authors even use, as support for their argument, the old textbook example of how a sheep farmer cannot choose to produce wool alone, or mutton alone, but only some combination of these, but there are some readers who will ask whether there may nevertheless be a case for a less cursory examination of the economic advantages of traffic segregation. Most of the argument of the report is, however, taken up with a consideration of the various systems upon which the costs of operating roadway systems should be apportioned, and there is an air of didactic certainty about the way in which the report comes round, after much judicious consideration of other possibilities, to the view of what is called "long-run marginal cost pricing" - the impeccable principle that road users of different kinds should be saddled with that proportion of the total cost of building and maintaining the road system which is attributable to the use they make of it.

The trouble, as the report repeatedly acknowledges, is that there is an enormous gap between principle and practice. Thus in estimating the proportion of the capital expenditure on roads to be attributed to different kinds of vehicles, the ministry's argument has to rely on the rule of thumb that a heavy goods vehicle should bear twice as high a cost as a private car. Readers will be tempted to ask why this number is a better guide to good practice than the number three which the Ministry of Transport used in its evidence to the Geddes committee some years ago. Owners of heavy goods vehicles will more pertinently want to know how a calculation which involves such a large uncertainty can be used to justify an increase of about 5 per cent ( $£ 30$ million a year) of the taxes levied on road users both directly and by means of fuel, especially when this increase falls exclusively on heavy goods vehicles. In the same way, there is more than a trace of arbitrariness in the way in which the ministry argues that if heavier vehicles tend to travel greater distances, there is a case for increasing the annual tax which they must pay. Is there not at least an equal case for putting up the fuel tax ?

These, however, are comparatively minor reasons for believing that the ministry has set out to design a basis for costing which is much more refined than circumstances will at present allow. The practical conclusion which is likely to be made much use of in the House of Commons in the weeks ahead is that the goods vehicles are responsible for 28.9 per cent of the cost of operating the British road system, but that they contribute only $24 \cdot 8$ per cent of the revenue raised from all road users. Its particular weakness is that the uncertainties of the calculation may be much greater than the difference between the two percentages. A more serious difficulty, however, is that the amount of revenue raised by taxation is roughly twice the cost of operating the road system in Britain. In circumstances like these, there is, of course, no point in seeking delicately to balance costs and receipts-and there is no serious hope of attempting to explain away the difference by vague talk about the "community cost" of air pollution and the like. The real truth is that British governments have decided to tax road transport of all kinds more heavily than costs alone would justify, and within this framework it is-and should be -a political matter to decide which kinds of road users should be let off most lightly. This, for example, is the spirit in which public service vehicles are undertaxed-and will continue to be. At a time at which the health of British industry is in everybody's mind, it would have been understandable if the Ministry of Transport bad sought to reduce the costs of industrial transport. But it is, of course, well known that the ministry would like to divert some heavy road traffic to the railways (which at present cost a subsidy of nearly half the cost of running the British roads) and that is a legitimate intention if the object is really to make better use of under-used resources. And that, as it happens, would be a calculation of the kind to which the ministry's marginal costings could be much more accurately applied. In the homely language of the economists, this would not be a matter of asking sheep farmers to produce mutton and no wool, but of asking them whether they would like to produce cattle instead. 